\title{
The Use of the Japanese Public Financial Support Has Positive Impact on Persistence with Outpatient Treatments for Schizophrenia: Single-center Retrospective Cohort Study in Japan
}

This article was published in the following Dove Press journal:

Patient Preference and Adherence

\author{
Masatoshi Arikawa (iD) \\ Kazumi Ota ${ }^{2}$ \\ Takaharu Azekawa (D) \\ Shizuko Ohashi ${ }^{1}$ \\ Yoichi Funaoka' \\ Hiroshi Yoshiie' \\ Haruka Koshi' \\ Yohei Takaishi' \\ Saeka Nakao' \\ 'Department of Psychiatry, Shioiri Mental \\ Clinic, Yokosuka, Kanagawa, Japan; \\ ${ }^{2}$ Department of Psychiatry, Juntendo \\ University School of Medicine, Tokyo, \\ Japan
}

\begin{abstract}
Purpose: One of the challenges of treating schizophrenia is how to improve persistence with outpatient treatments. Lengthening community life by improving persistence and preventing relapse and rehospitalization can have positive influence on the patients' personal recovery and well-being. In Japan, there is "Medical Expenses for Services and Supports for Persons with Disabilities" ("Jiritsu-shien-iryo-hi" in Japanese) which is the public financial support system for psychiatric outpatient treatments. However, it is not clear how this financial support affects persistence with outpatient treatments for patients with schizophrenia. The purpose of the study is to investigate how the financial support affects persistence with outpatient treatments for schizophrenia.
\end{abstract}

Patients and Methods: Data of outpatients who visited the clinic between October 1, 2006 and September 30, 2016 was collected. The variables for the analysis were continuation and discontinuation of treatment of those who used the financial support (user) and those who did not (nonuser). The covariates were sex, age, time from onset of the disease to first visit to the clinic, number of hospitalizations in the past, use of psychiatric day care, and use of psychiatric home nursing care. Kaplan-Meier analysis was performed using propensity score matching. The observation period was five years from the first visit to the clinic.

Results: Among 1155 patients who were diagnosed with schizophrenia, 718 were excluded, based on the exclusion criteria. The propensity score matching was performed for 437 patients, and the subjects for the final analysis were 278. Average survival period was 1.09 ( $\mathrm{SD} \pm 1.66$ ) years for nonuser, 3.02 ( $\mathrm{SD} \pm 1.77$ ) years for users, and users exhibited a significantly longer number of years of outpatient treatments $(P<0.001)$.

Conclusion: The results indicated that use of the financial support can contribute to persistence with outpatient treatments.

Keywords: schizophrenia, treatment persistence, financial support, jiritsu-shien-iryo-hi

\section{Introduction}

Schizophrenia is one of the chronic psychiatric diseases which can severely affect people's daily lives and social functions including employment. ${ }^{1}$ The recommended treatment of schizophrenia is the combination of drug treatment and psychosocial treatment in which the patients, families, and professionals work collaboratively based on the recovery-oriented practice. ${ }^{2,3}$ However, there is a report that 40 to $60 \%$ of patients with schizophrenia suffer from significant lifelong impairments, and an additional 20 to $40 \%$ will have lifelong moderate impairments. ${ }^{4}$ The risk factors
Correspondence: Masatoshi Arikawa Department of Psychiatry, Shioiri Mental Clinic, Yokosuka, Kanagawa, Japan Email masatoshi.arikawa@gmail.com
Patient Preference and Adherence 2021:15 169-175 
which can reduce the quality of life of the patients include relapse, rehospitalization, and treatment drop-out. ${ }^{5}$ Approximately $80 \%$ of the patients experience relapse within five years after initial recovery, and discontinuing antipsychotic drug therapy can increase the risk of relapse by almost five times. ${ }^{5}$ In addition, 20 to $80 \%$ of the patients with schizophrenia fail to take medication properly. ${ }^{6}$ Therefore, improving adherence to and persistence with treatments is important for personal recovery ${ }^{7,8}$ and well-being of the patients with schizophrenia. ${ }^{9}$ According to review articles which examined clinical interventions for improving medication adherence in psychosis, the effect of clinical intervention is limited in the long-term. ${ }^{3,10}$ In contrast, several studies reported that financial incentives as a social resource can have positive impact on improving medication adherence and persistence with outpatient treatments. ${ }^{11,12}$

According to the previous study, ${ }^{13}$ the direct health care costs of schizophrenia under health insurance in Japan are approximately 602,771 million yen for inpatient and 148,047 yen for outpatient, and the inpatient costs are over four times more than outpatient costs. As for the indirect costs, the costs imposed by unemployment constitute the largest component in schizophrenia while in depression and anxiety disorders, absenteeism which is the productivity loss caused by absence from work, and presenteeism which is the productivity loss while at work are the biggest part of the indirect costs. ${ }^{13}$ Therefore, it is important to improve persistence with outpatient treatments, prevent rehospitalization, and to ameliorate social functions of schizophrenia not only in order to increase the well-being of individuals, but also to reduce the societal burden caused by schizophrenia.

In Japan, there is a public financial support system called "Medical Expenses for Services and Supports for Persons with Disabilities" ("Jiritsu-shien-iryo-hi" in Japanese) (financial support) to reduce the copayment for the psychiatric outpatient treatments. However, to the best of our knowledge, there has been no study to examine how this indirect financial incentive affects persistence with treatments for the patients. In the present study, we compared retrospectively the days until discontinuation of outpatient treatments between those who used the financial support (user) and those who did not (nonuser). We hypothesized that if the financial support has a positive impact on persistence with outpatient treatments, it can be one of the resources that can help to lengthen community life of the patients with schizophrenia.

\section{Patients and Methods}

\section{Subjects}

Among all the patients who first visited Shioiri Mental Clinic from October 1, 2006 until September 30, 2016, those who were diagnosed with schizophrenia (F20-F29 in the International Classification of Diseases, 10th Revision; ICD-10) ${ }^{14}$ were selected.

The observation period was five years from the first visit to the clinic. Discontinuation of treatment was defined as death, no visit to the clinic for more than 30 days, hospitalization, and admission to psychiatric facilities. ${ }^{15}$

\section{Financial Support System for Psychosis in Japan}

1) The Medical Expenses for Services and Supports for Persons with Disabilities (financial support) under the Act on the Comprehensive Support for the Daily and Social Life of Persons with Disabilities is the financial support from the public expense to reduce medical copayments. Japan's universal health insurance system provides comprehensive coverage to all Japanese citizens, and medical copayment rate is $30 \%$ for elementary school up to age 69 . However, by using this financial support, self-pay burden is $10 \%$ and the remaining $20 \%$ is covered by the public expenses (national $50 \%$, prefectures $50 \%$ ). ${ }^{16,17}$

2) In order to utilize the financial support, one needs to get a doctor's note and apply through a city hall in his/her local community. Utilization of the financial support is considered when a patient desires or a doctor or other health-care provider recommends. The doctor and the patient should agree on using the financial support before applying for it.

3) The financial support applies to the costs for outpatient visits, antipsychotic medications, psychiatric day care, and home nursing care for all kinds of psychosis. It is not applied to the costs for hospitalization. ${ }^{16,17}$

4) Persons who earn under a certain level of income are qualified for the financial support. The ceiling is set for copayment according to income level. ${ }^{18}$

\section{Exclusion Criteria}

The exclusion criteria were persons who are over the age of 70 and under the age of 15 , those who used the previous financial support system and moved to the current one which has been effective since April 2006, those who visited the clinic only once for the second opinion, police detention, those whose information is in the clinic because the emergency center asked for advice, and those with missing data. 


\section{Data Collection}

We retrospectively collected the patients' information from their medical records. The collected data for covariates were the patient's sex, age at the time of their first visit to the clinic, days from onset of symptoms to first visit to the clinic, number of hospitalizations, use of the financial support, days from the first visit to the clinic to the use of the financial support, use of psychiatric day care, and use of home nursing care. Use of psychiatric day care or home nursing care were assessed as 0 (not used) or 1 (used), and duration (days) of psychiatric day care or home nursing care were not counted. Main outcome variables are days until discontinuation of treatment defined as death, no visit to the clinic for more than 30 days, hospitalization, and admission to psychiatric facilities.

\section{Ethical Considerations}

This study was conducted in accordance with the Declaration of Helsinki and Japanese Ethical Guidelines for the Epidemiological Research. Prior to initiating the present study, the research protocol was reviewed and approved by the Ethics Committee of the Japanese Association of Neuro-Psychiatric Clinics (ID: 2019-15), to which Shioiri Mental Clinic belongs.

Because the present study was conducted by posting information that does not identify an individual from existing materials, informed consent was waived. However, prior to initiating the data collection, a public notice was made about the study which clarified that it was possible for the patients and their families to refuse to participate in the research if it was not approved, and that the patients and their families can make inquiries about the study to medical institution managers at any time.

We allocated research IDs to all subjects for the protection of personal information, managed them on computers in the workplace that could not be connected to the Internet, and only the researchers of the present study had access to the data.

\section{Statistics}

In this study, the subjects were divided into two groups; those who utilized the financial support (user group) and those who did not (nonuser group). The observational period was five years from their first visit to the clinic. Days until discontinuation of treatment were counted for each patient and the two groups were compared. Time until discontinuation of treatment was estimated by Kaplan-Meier method in the two groups with 0 as continuation of treatment and 1 as discontinuation of treatment. We considered discontinuation of treatment when a patient stopped visiting the clinic because of hospitalization, relapse, discharge from a hospital, death, nursing home placement, and absence of outpatient visit over 30 consecutive days. For those patients who stopped coming to the clinic because they were told by the doctor to do so, or because they changed the clinic or residence with the doctor's note was considered continuation of treatment.

Two groups were compared by log rank test. $P<0.05$ was considered significant. Objective variables were days until discontinuation of outpatient treatments in user group and nonuser group. Explanatory variables were age, sex, number of hospitalization, and duration of illness. Fisher's exact test was used to compare the two groups. In order to control the explanatory variables in the two groups, we used propensity score matching ${ }^{19-21}$ which allows two groups to have statistically equal demographics compatible with randomization. Among several propensity score matching estimators, we used nearest neighbor matching, which is a method to select the individual from the control group as a matching partner for a treated individual that is closest in terms of propensity score. Covariates were age, sex, number of hospitalization and duration of illness. The difference between the two groups was evaluated with Fisher's exact test. Easy-R (EZR) ${ }^{22}$ was used for all the statistical procedures. We used the same statistical procedure as our previous studies. ${ }^{23,24}$ The average days from the first visit to the clinic until the initiation of the financial support was also calculated.

\section{Results}

Among 16,153 patients, 1155 were diagnosed as F20-F29 in ICD-10. Out of 1155 patients, 718 patients met exclusion criteria. Four hundred and eighty-one patients who were over 70 years old and 11 patients who were under 15 years old were excluded because other financial medical support was available to them. One hundred and ninety-eight patients used the previous financial support system and moved to the current one, seven patients visited our clinic only once for a second opinion, five patients were in police detention, and 16 patients had missing data. After excluding 718 patients who met the exclusion criteria, 437 were the subject of the present study. The process of subject selection is shown in Figure 1.

After the propensity score matching, 278 subjects ( $\mathrm{N}=139$ in the user group, $\mathrm{N}=139$ in nonuser group) were 


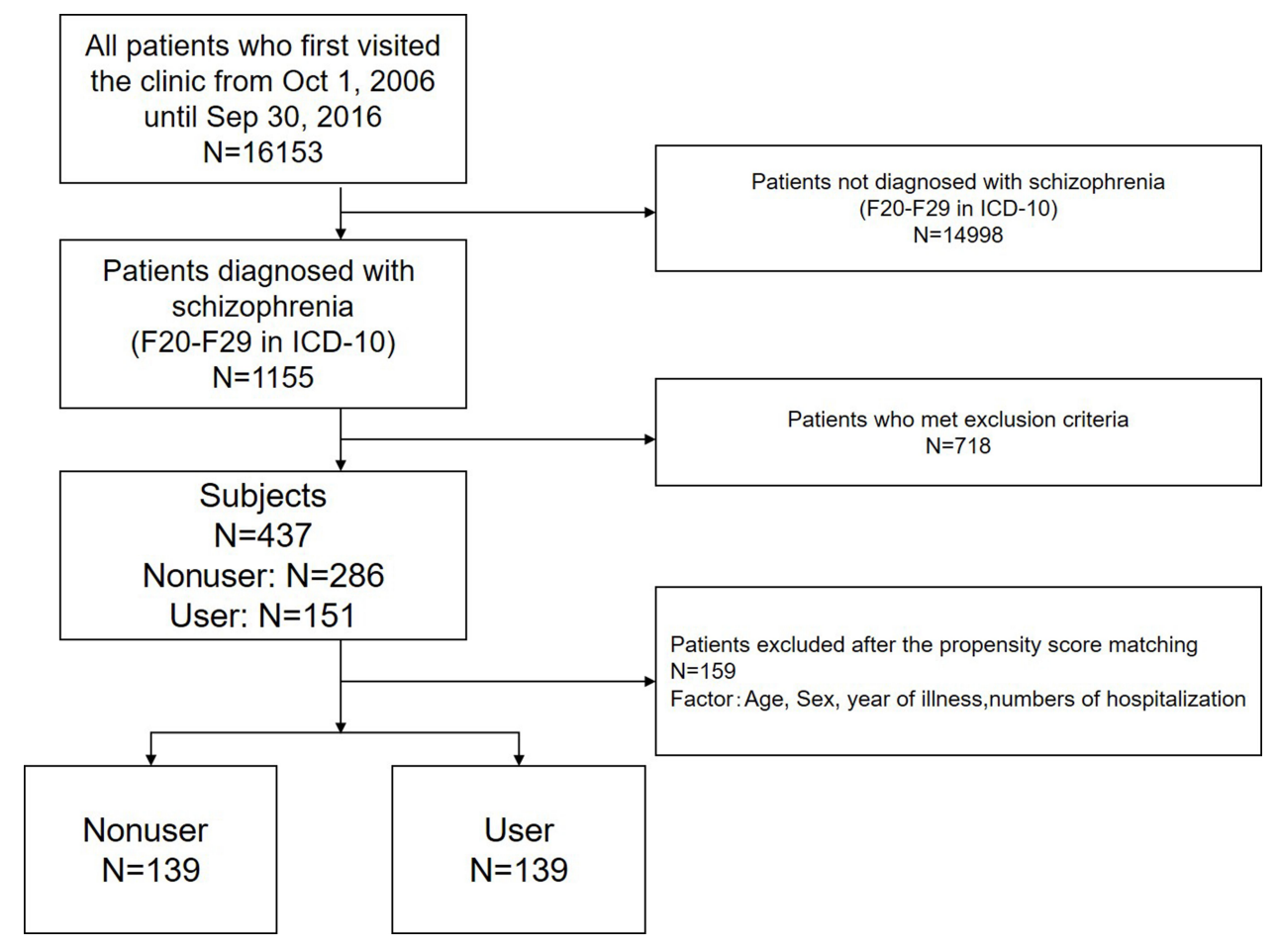

Figure I The process of subject selection.

Abbreviations: ICD-10, International Classification of Diseases, I0th Revision.

selected. There was no significant difference between the two groups in sex, age, duration of illness and number of hospitalization (Table 1). The average days from the first visit to the clinic until the initiation of the financial support was 188.27 ( $\mathrm{SD} \pm 306.96)$. Day care was used by 29 patients (19.7\%) in the user group and none used in the nonuser group $(P<0.001)$, and home nursing care was used by 13 patients $(8.8 \%)$ in the user group and five patients $(1.9 \%)$ in the nonuser group $(P<0.002)$.

Table I The Data of User and Nonuser Groups After the Propensity Score Matching

\begin{tabular}{|c|c|c|c|}
\hline$N=278$ & $\begin{array}{l}\text { User } \\
N=139\end{array}$ & $\begin{array}{l}\text { Nonuser } \\
N=139\end{array}$ & $P$ \\
\hline Sex (male), n (\%) & $61(43.9)$ & $63(45.3)$ & 0.904 \\
\hline Mean age (SD) & $39.88(13.92)$ & $38.29(14.61)$ & 0.356 \\
\hline Mean years of illness (SD) & $10.18(10.64)$ & $9.58(11.08)$ & 0.643 \\
\hline $\begin{array}{l}\text { Mean numbers of } \\
\text { hospitalization (SD) }\end{array}$ & $0.86(1.58)$ & $0.79(2.22)$ & 0.756 \\
\hline Day care use, n (\%) & $26(19.1)$ & $0(0.0)$ & $<0.001$ \\
\hline $\begin{array}{l}\text { Home nursing care use, } \\
\text { n (\%) }\end{array}$ & II (8.I) & I (0.7) & 0.005 \\
\hline $\begin{array}{l}\text { Mean days until the use of } \\
\text { financial supports (SD) }\end{array}$ & $\begin{array}{l}188.27 \\
(306.96)\end{array}$ & - & \\
\hline
\end{tabular}

As for the continuation of treatment, which was the primary outcome in this study, the subjects continued receiving treatment for $1.09(\mathrm{SD} \pm 1.66)$ years in average in the nonuser group and $3.02(\mathrm{SD} \pm 1.77)$ years in average in the user group, and the user group continued outpatient treatments significantly longer than the nonuser group (Figure 2).

The reasons for discontinuation of outpatient treatments in the nonuser group were stopped coming to the clinic based on their own judgement $(\mathrm{N}=55,39.5 \%)$, relapse or rehospitalization $(\mathrm{N}=24,17.3 \%)$, moving or changing the clinic $(\mathrm{N}=18,12.9 \%)$, nursing home placement $(\mathrm{N}=4,2.9 \%)$, suicide $(\mathrm{N}=1,0.7 \%)$, and termination of outpatient treatments $(\mathrm{N}=13,9.4 \%)$. The reasons for discontinuation of outpatient treatments in the user group were stop coming to the clinic based on their own judgement $(\mathrm{N}=20,14.0 \%)$, relapse or rehospitalization ( $\mathrm{N}=13,9.0 \%)$, moving or changing the clinic $(\mathrm{N}=10,7.0 \%)$, death $(\mathrm{N}=3,2.0 \%)$, and termination of outpatient treatments $(\mathrm{N}=5,4.0 \%)$.

\section{Discussion}

The results suggest that using the financial support contributes to persistence with outpatient treatments for schizophrenia in Japan. This result supports previous studies which indicate that financial incentive can improve adherence to and persistence with outpatient treatment for 


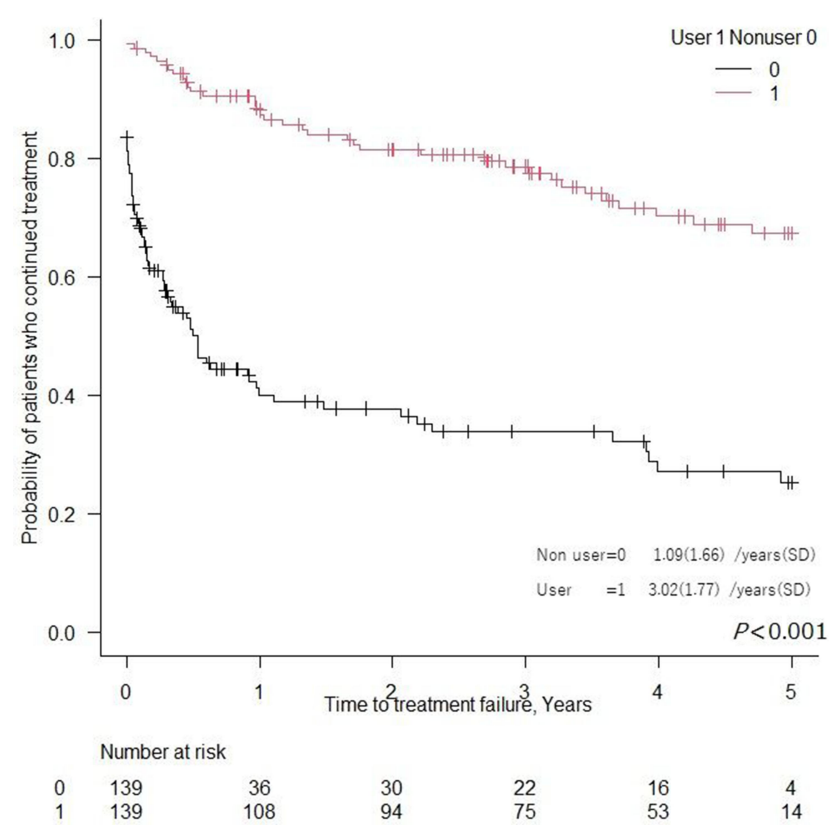

Figure 2 Kaplan-Meier analytics for time to discontinuation of treatment comparisons between the two groups.

Notes: Nonuser group 1.09 (SD \pm 1.66 ) years, user group $3.02(S D \pm 1.77)$ years, $P<0.001$.

patients. $^{11,12}$ The present study also indicate that even the indirect financial incentive can have a positive impact on the outpatient persistence for schizophrenia.

The commonly reported weakness of financial incentive intervention can be the potential for new, external motivators to depress intrinsic motivation and harm, rather than sustain, postintervention behaviors. ${ }^{25}$ However, most of the research on financial incentive to promote desirable health behaviors including outpatient visits use cash or voucher. It is not clear if financial incentive such as reducing certain percentage of copayment has the same kind of weakness because of the lack of research that directly compares design feature attributes such as cash vs noncash. ${ }^{25}$ The further study is needed to clarify ethical and conceptual differences of different types of financial incentive and their effect on persistence with outpatient treatments for schizophrenia.

The financial support for psychiatric patients in Japan is applied to the costs for outpatient treatments along with that of psychiatric day care and home nursing care. The financial support users in the present study are more likely than nonusers to utilize day care or home nursing care, which can have positive impact on the continuation of treatment. ${ }^{23,24,26}$ The multiple factors of the psychiatric day care including support from various professionals, encounters with people who have similar recovery goals, and shared decision making in which the patients can be actively involved in the decision-making process regarding their treatments can contribute to adherence to treatment for schizophrenia. ${ }^{23,24}$ Close monitoring of the clinic visits by using the outreach team, including nurses, would be of help for patients with schizophrenia to prevent an irregular pattern of clinic visits and to prevent rehospitalization. ${ }^{26}$ Therefore, the use of day care or home nursing care in addition to less financial burden for the outpatient visits and medication can encourage patients to continue their outpatient treatment.

The financial incentive can be effective especially for low-income populations to improve adherence to healthrelated behaviors such as outpatient visits and vaccinations. ${ }^{27}$ According to the survey answered by 1587 people in Japan, ${ }^{28} 52.6 \%$ of the financial support users are from low-income households with an annual income of lower than two million yen, and $26.6 \%$ are from the households with annual income of two to four million yen. Average annual income in Japan is approximately 5.6 million yen (the median is approximately 4.4 million yen). ${ }^{29}$ These data indicate that in Japan the majority of the financial support users are from low-income households, and the financial support tends to enable these populations to continue outpatient treatments and use of psychiatric day care and home nursing care. In the Health Insurance Experiment (HIE) in the RAND study, individuals under the age of 65 were randomly assigned to different types of health insurance plans which involved varying levels of copayment: $0 \%$, $25 \%, 50 \%$, or $95 \%$. As a result, copayment reduced the use of nearly all health services including mental health treatment. ${ }^{30}$ In Japan, as the amount of medical copayment increases, demand for medical care greatly decreases among the families of patients. ${ }^{31}$ These reports indicate that the amount of financial incentive can impact on continuation of treatments including outpatient treatments.

Another finding of the present study is that discontinuation of outpatient treatment is likely to happen within a year from the first visit to the clinic, and the average days from the first visit to the clinic until the initiation of the financial support was 188.27. These results suggest that it is crucial to start using the financial support in the early stage of the treatments. However, some people do not have opportunities to know about the financial support. According to the survey, ${ }^{28} 78.1 \%$ of the financial support users learned about it at medical institutions, and $8.3 \%$ of them from their families and friends. Therefore, it is 
largely up to the primary doctors or other medical professionals whether the patients get to know about the financial support. In Japan, the financial support is initiated by the application of a person requiring protection or his/her relatives living together. This kind of application system can possibly impede the use of the financial support. In addition, there can be several other factors that can inhibit people from using the financial support. (1) The amount of money one gets from the financial support is based on one's income from the previous year, and he/she may not qualify for the financial support if the income was higher than a certain level. (2) Some people do not spend the minimum amount of medical costs to receive the financial support. (3) Structural stigma defined as societal-level condition, cultural norms, and institutional policies that constrain the opportunities, resources, and well-being of the individuals with mental illness ${ }^{32}$ can inhibit people from applying for the financial support. The challenges to improve persistence with outpatient treatments for schizophrenia in Japan include when and how to inform patients of the financial support and how to minimize structural stigma of mental illness and receiving social support. The further study is needed to examine how to conquer these challenges.

\section{Limitations}

The main limitations in the present study are the biases. Patients' educational level, income, stage of recovery, types and dose of medication, possible side effects of the medication, types and frequency of psychosocial intervention for the day care participants can influence both the persistence with outpatient treatments and usage of financial supports. In addition, the fact that only the low- and middle-income patients can apply for this financial support can constitute another selection bias. The present study is retrospective in nature and it was not possible to eliminate all the selection biases. Further study with robust regression models using instrumental variables is needed to limit biased estimates. $^{33}$

There are also other limitations in this study. (1) It was undertaken in a single facility. (2) Psychosis was not evaluated. ${ }^{34,35}$ (3) Days of psychiatric day care or home nursing care were not counted, and the availability of caregivers and other social welfare services were not taken into consideration. (4) Not all the doctors at the clinic suggest the use of the financial support to all the patients with schizophrenia.

\section{Conclusion}

The present study indicates that the use of the financial support can contribute to improved persistence with outpatient treatments of patients with schizophrenia. It needs to be clarified in the further research when and how to inform the financial support to the patients and how to minimize structural stigma of mental illness and of receivingsocial support.

\section{Acknowledgment}

The authors thank for Ayako Oura for her advice, Chikara Hashidume, Reina Fushikida, Takahito Nagumo, Ai Iida for their support as a research team. The authors are also grateful for the support from the Shioiri Mental Clinic.

\section{Disclosure}

Takaharu Azekawa reports speaker's honoraria from Eli Lilly, Mochida Pharmaceutical Co. Ltd, Otsuka Pharmaceutical, and Pfizer, outside the submitted work. The authors report no other conflicts of interest in this work.

\section{References}

1. Rubin A, Springer DW, Trawver K, eds. Clinician's Guide to Evidence-Based Practice Psychosocial Treatment of Schizophrenia. New Jersey: Wiley \& Sons; 2010.

2. Liberman RP. Recovery from Disability: Manual of Psychiatric Rehabilitation. Washington DC: American Psychiatric Publishing Inc; 2008.

3. El-Mallakh P, Findlay J. Strategies to improve medication adherence in patients with schizophrenia: the role of support services. Neuropsychiatr Dis Treat. 2015;11:1077-1090. doi:10.2147/NDT. S56107

4. Crown WH, Neslusan C, Russo PA, Holzer S, Ozminkowski R, Croghan T. Hospitalization and total medical costs for privately insured persons with schizophrenia. Adm Policy Ment Health. 2001;28:335-351. doi:10.1023/A:1011139215761

5. Robinson D, Woerner MG, Alvir JMJ, et al. Predictors of relapse following response from a first episode of schizophrenia or schizoaffective disorder. Arch Gen Psychiatry. 1999;56(3):241-247. doi:10. 1001/archpsyc.56.3.241

6. Novick D, Haro JM, Suarez D, Perez V, Dittmann RW, Haddad PM. Predictors and clinical consequences of non-adherence with antipsychotic medication in the outpatient treatment of schizophrenia. Psychiatry Res. 2010;176(2-3):109-113. doi:10.1016/j.psychres.20 09.05.004

7. Slade M, Amering M, Oades LG. Recovery: an international perspective. Epidemiol Psichiatr Soc. 2008;17(2):128-137. doi:10. 1017/S1121189X00002827

8. Leamy M, Bird V, Le Boutillier C, Williams J, Slade M. Conceptual framework for personal recovery in mental health: systematic review and narrative synthesis. $B r J$ Psychiatry. 2011;199(6):445-452. doi:10.1192/bjp.bp.110.083733

9. Kuwabara H, Saito Y, Mahlich J. Adherence and rehospitalizations in patients with schizophrenia; evidence from Japanese claim data. Neuropsychiatr Dis Treat. 2015;11:935-940.

10. Nosé M, Barbui C, Gray R, Tansella M. Clinical interventions for treatment non-adherence in psychosis: meta-analysis. $\mathrm{Br}$ J Psychiatry. 2003;183:197-206. doi:10.1192/bjp.183.3.197 
11. Giuffrida A, Torgerson DJ. Should we pay the patient? Review of financial incentives to enhance patient compliance. BMJ. 1997;315 (7110):703-707. doi:10.1136/bmj.315.7110.703

12. Priebe S, Yeeles K, Bremner S. Effectiveness of financial incentives to improve adherence to maintenance treatment with antipsychotics: cluster randomised controlled trial. BMJ. 2013;347(7930):f5847. doi:10.1136/bmj.f5847

13. Sado M, Inagaki A, Koreki A, et al. The cost of schizophrenia in Japan. Neuropsychiatr Dis Treat. 2013;9:787-798. doi:10.2147/NDT. S41632

14. World Health Organization. The ICD-10 Classification of Mental and Behavioural Disorders: Clinical Descriptions and Diagnostic Guidelines. Geneva: World Health Organization; 1992.

15. Kishimoto T, Agarwal V, Kishi T, Leucht S, Kane JM, Correll CU. Relapse prevention in schizophrenia: a systematic review and meta-analysis of second-generation antipsychotics versus first-generation antipsychotics. Mol Psychiatry. 2013;18:53-66. doi: $10.1038 / \mathrm{mp} .2011 .143$

16. Ministry of Health, Labour and Welfare [PDF on the Internet]. Tokyo. Medical system for services and supports for personas with disabilities; 2020. Available from: https://www.mhlw.go.jp/english/ wp/wp-hw5/dl/23010902e.pdf. Accessed August 24, 2020.

17. Ministry of Health, Labour and Welfare [PDF on the Internet]. Tokyo. System of medical payment for services and supports for persons with disabilities; 2010. Available from: https:/www.mhlw. go.jp/english/wp/wp-hw4/dl/health_care_and_welfare_measures for_people_with_physical_disabillities/2011071904.pdf. Accessed August 24, 2020.

18. Ministry of Health, Labour and Welfare. [PDF on the Internet]. Tokyo. Health care and welfare measures for persons with disabilities: benefits for welfare services and supports for persons with disabilities; 2011. Available from: https://www.mhlw.go.jp/english/ wp/wp-hw6/dl/09e.pdf. Accessed August 24, 2020.

19. Rosenbaum PR, Rubin DB. The central role of the propensity score in observational studies for causal effects. Biometrika. 1983;70 (1):41-55. doi:10.1093/biomet/70.1.41

20. Stukel TA, Fisher ES, Wennberg DE, Alter DA, Gottlieb DJ, Vermeulen MJ. Analysis of observational studies in the presence of treatment selection bias: effects of invasive cardiac management on AMI survival using propensity score and instrumental variable methods. JAMA. 2007;297(3):278-285. doi:10.1001/jama.297.3.278

21. Connors AF, Speroff T, Dawson NV, et al. The effectiveness of right heart catheterization in the initial care of critically III patients. JAMA. 1996;276(11):889-897. doi:10.1001/jama.1996.03540110043030

22. Kanda Y. Investigation of the freely available easy-to-use software 'EZR' for medical statistics. Bone Marrow Transplant. 2013;48: 452-458. doi:10.1038/bmt.2012.244
23. Arikawa M, Ota K, Azekawa T. The influence of psychiatric day care on the continuation of treatment for patients with schizophrenia: a retrospective cohort study in Japan. Soc Work Ment Health. 2019;17:1-12. doi:10.1080/15332985.2019.1610543

24. Arikawa M, Ota K, Azekawa T. The influence of the psychiatric day care on the continuation of treatments for the patients with bipolar disorder: single-center retrospective cohort study in Japan. Soc Work Ment Health. 2020;18:1-11. doi:10.1080/15332985.2020.1726552

25. Mitchell MS, Goodman JM, Alter DA, et al. Financial incentives for exercise adherence in adults: systematic review and meta-analysis. $\mathrm{Am}$ J Prev Med. 2013;45(5):658-667. doi:10.1016/j.amepre.2013.06.017

26. Suzuki Y, Yasumura S, Fukao A, Otani K. Associated factors of rehospitalization among schizophrenic patients. Psychiatry Clin Neurosci. 2003;57(6):555-561. doi:10.1046/j.1440-1819.2003.01167.x

27. Sutherland K, Christianson JB, Leatherman S. Impact of targeted financial incentives on personal health behavior. Med Care Res Rev. 2008;65(6_suppl):36S-78S. doi:10.1177/1077558708324235

28. Ministry of Health, Labour and Welfare [PDF on the Internet]. Tokyo. Results of the survey conducted to the recipients of the medical expenses for services and supports for persons with disabilities; 2017. Available from: https:/www.mhlw.go.jp/file/05-Shingikai-12601000Seisakutoukatsukan-Sanjikanshitsu_Shakaihoshoutantou/0000185303. pdf. Accessed August 24, 2020.

29. Ministry of Health, Labour and Welfare [PDF on the Internet]. Tokyo. Comprehensive survey of living conditions; 2018. Available from: https://www.mhlw.go.jp/toukei/saikin/hw/k-tyosa/k-tyosa17/dl/ 10.pdf. Accessed August 24, 2020.

30. Brook RH, Keeler EB, Lohr $\mathrm{KN}$, et al. The Health Insurance Experiment: A Classic RAND Study Speaks to the Current Health Care Reform Debate. Santa Monica, CA: RAND Corporation; 2006.

31. Yoshida A, Takagi S. Effects of the reform of the social medical insurance system in Japan. Japan Econ Rev. 2002;53:444-465. doi:10.1111/1468-5876.00238

32. Hatzenbuehler ML. Structural stigma: research evidence and implications for psychological science. Am Psychol. 2016;71(8):742-751. doi:10.1037/amp0000068

33. Jiang Y, Ni W. Estimating the impact of adherence to and persistence with atypical antipsychotic therapy on health care costs and risk of hospitalization. Pharmacotherapy. 2015;35(9):813-822. doi:10.1002/ phar. 1634

34. Suzuki T, Uchida H, Watanabe K, Kashima H. Treatment target in schizophrenia: a critical review and a clinical suggestion. Psychopharmacol Bull. 2008;41(4):80-102.

35. Suzuki T. Which rating scales are regarded as 'the standard' in clinical trials for schizophrenia? A critical review. Psychopharmacol Bull. 2011;44(1):18-31.
Patient Preference and Adherence

\section{Publish your work in this journal}

Patient Preference and Adherence is an international, peer-reviewed, open access journal that focusing on the growing importance of patient preference and adherence throughout the therapeutic continuum. Patient satisfaction, acceptability, quality of life, compliance, persistence and their role in developing new therapeutic modalities and compounds to optimize clinical outcomes for existing disease states are major areas of interest for the journal. This journal has been accepted for indexing on PubMed Central. The manuscript management system is completely online and includes a very quick and fair peer-review system, which is all easy to use. Visit http:// www.dovepress.com/testimonials.php to read real quotes from published authors. 